\title{
O poder militar como instrumento da política externa brasileira contemporânea
}

\author{
Military Power as Brazil's Contemporary Foreign Policy Tool
}

JOÃO PAULO SOARES ALSINA JR*

Rev. Bras. Polít. Int. 52 (2): 173-191 [2009]

\section{Introdução}

Neste artigo pretende-se responder a três perguntas: a) qual é a instrumentalidade do poder militar para a condução da política externa de Estados periféricos no pós-Guerra Fria?; b) qual é a instrumentalidade do poder militar para a condução da política externa brasileira contemporânea?; e c) como é possível aumentar o grau de articulação entre a política externa e a política de defesa tendo por base cenários prospectivos que levem em conta a interação entre os planos doméstico e internacional?

As respostas, ainda que parciais, às perguntas mencionadas são essenciais para que seja factível discutir a temática da articulação entre as políticas externa e de defesa a partir de um arcabouço conceitual mínimo. A necessidade de exploração de conceitos basilares dá-se pela constatação de que os assuntos de defesa carecem de tratamento mais aprofundado no Brasil. A repetição acrítica de visóes simplistas sobre o problema frequentemente empobrecem o (pífio) debate público, reforçando esteriótipos e tornando adicionalmente incompreensível para o cidadão comum questōes relevantes que, por suas implicaçōes, deveriam ser objeto de análises sérias e informadas. Logo, este texto possui um inevitável caráter didático, visando a contribuir para o adensamento das discussóes sobre o lugar do poder militar na política externa de um Estado com as características peculiares do Brasil.

\section{Definição de poder, poder militar e Estado periférico}

Embora o poder seja uno, ele se manifesta sob as mais diferentes formas, nas mais diferentes circunstâncias. Como relação social, o poder pode ser compreendido no contexto de teorias do tipo agente/principal, já que é muitas vezes possível determinar quem exerce o poder e quem sofre os efeitos daquela

\footnotetext{
* Mestre em Relações Internacionais pela Universidade de Brasília - UnB e diplomata de carreira (jalsina@ mre.gov.br).
} 
ação. Essa possibilidade, contudo, deve ser encarada com cuidado. Tendo em conta que uma das características intrínsecas do poder é seu caráter relacional, em nenhuma circunstância haverá açôes exclusivamente unilaterais - em que o sujeito impóe sem resistência sua vontade a um objeto inerte, indefeso. Em toda e qualquer relação, o alvo do poder (agente) terá a opção de resistir àquele que o impõe (mandante). Quase sempre, agente e mandante negociarão como a relação de poder ocorrerá, pois o primeiro, mesmo em posição subalterna, geralmente possui alternativas capazes de modular o grau de impositividade do segundo. Ademais, interessa ao mandante que seu relacionamento com o agente seja o menos conflitivo possível, uma vez que quanto maior o grau de consentimento do agente, maior será a efetividade e a possibilidade de reprodução da relação de poder. Inversamente, quanto maior o conteúdo de coerção, menor a efetividade e a reprodutibilidade da relação ao longo do tempo.

Se é correto encarar o poder como capacidade que gera efeitos no plano das relações sociais, deve-se admitir que ele não precisa ser efetivamente exercido para produzir resultados. $\mathrm{O}$ poder de um mandante será tanto maior quanto maior for sua capacidade de limitar a margem de escolha do agente. Este, consciente da limitação, muitas vezes antecipa-se à ação daquele, fazendo sua vontade antes mesmo que ela se manifeste. Portanto, o poder como potência representa uma virtualidade que têm conseqüências palpáveis. No limite, não haveria sequer a necessidade de que o poder existisse concretamente, uma vez que bastaria a percepção da sua existência para a produção de efeitos - o que demonstra como o aspecto perceptual é ele próprio uma das facetas mais importantes do poder. Em vista disso, valeria abordar o que Scott classifica como os dois modos fundamentais de poder: a influência corretiva e a persuasiva, associados, respectivamente, ao que chama corrente principal e segunda corrente dos estudos sobre poder. ${ }^{1}$ A corrente principal, influenciada por Weber, encara o poder como um bem distribuído entre instituições, porém finito. A luta pelo poder constituiria, assim, um jogo de soma zero, envolvendo níveis variados de conflito. Para a segunda corrente, de outra parte, o poder seria antes de tudo um meio de facilitação ou produção das relações sociais, estando disperso através da sociedade. $\mathrm{O}$ poder representaria um jogo de soma positiva, em que todos os atores intervenientes poderiam ser beneficiados.

Tanto a influência corretiva quanto a persuasiva constituem elementos centrais das estruturas de dominação existentes nas sociedades. A dominação centrada na influência corretiva realiza-se por intermédio da limitação do espectro de possibilidades de ação do agente, seja na forma de coerção (empregada pelos "leôes"), seja na de incentivos positivos ou de sedução (empregada pelas "raposas"). A dominação fundamentada na influência persuasiva, por sua vez, opera por meio do comprometimento, da lealdade, da confiança, compondo uma estrutura de formação discursiva. Esta pode ser subdividida em dominação derivada do

1 SCOTT, John. (2001) Power. Cambridge: Polity Press,. p.12-16. 
conhecimento ou expertise (empregada pelas "corujas") e dominação derivada do direito de comandar (empregada pelos "ursos")2. A última é de particular importância por salientar o papel da liderança como elemento fulcral do exercício e da manutenção do poder.

Se se aceita que a influência corretiva do poder é por vezes mais saliente no plano internacional do que no doméstico, passa a ser fundamental definir o poder militar como etapa prévia ao estudo do seu lugar no relacionamento entre as unidades estatais. Nye, por exemplo, sustenta que o poder militar expressar-se-ia por meio de ameaças, permitiria a coerção, dissuasão e proteção, além de dar origem a políticas governamentais como a diplomacia coercitiva, a guerra e as alianças ${ }^{3}$. $\mathrm{O}$ autor em tela menciona também a capacidade persuasiva do poder militar, que poderia, em situações específicas, gerar admiração, reconfortar, proteger, auxiliar os desvalidos etc. Nye apóia, portanto, a tese da unidade ontológica do conceito de poder. Assim, a força armada é passível de ser utilizada tanto de forma direta (violência física) quanto indireta (meios não violentos). Em sua versão indireta, aproxima-se da influência persuasiva tout court, embora se diferencie dela, sobretudo, por utilizar instrumentos distintos: o poder militar necessita de uma base material, ao passo que a persuasão levada a cabo pelas corujas ou pelos ursos é antes de tudo uma formação discursiva. Logo, a força armada, enquanto pilar da influência corretiva, constitui elemento indissociável do poder lato sensu.

Com base no acima exposto, um Estado periférico pode ser simplificadamente caracterizado a partir de seu não pertencimento ao núcleo central do capitalismo. Como corolário dessa exclusão, um Estado periférico apresentará disparidades domésticas em escala variável, porém mais acentuada do que a encontrada nos países centrais. A base institucional dos Estados da periferia tenderá a ser mais frágil que a do centro, assim como sua vulnerabilidade a influências externas. Não raro, essas fragilidades refletir-se-ão na existência de instabilidade doméstica - fato que representa preocupação adicional para os formuladores das políticas de segurança e defesa dos países periféricos. Assim, levando em conta a rationale desenvolvida até este ponto, infere-se que o poder militar é relevante para os países periféricos. Em não raras oportunidades, dada a tibieza institucional prevalecente na periferia, a força armada, encarnada nos exércitos nacionais, constitui a principal barreira à fragmentação pura e simples do Estado.

No entanto, a capacidade defensiva da periferia quase sempre se encontra limitada por constrangimentos diversos. Dada a heterogeneidade existente entre os Estados periféricos, pode-se conceber um contínuo de atribuição de importância ao poder militar que variará de acordo com a dotação de recursos de cada unidade, seus diferentes contextos domésticos e as estruturas material e social prevalecentes

2 Essa taxonomia política derivada da zoologia é citada por Scott como presente nas obras de Maquiavel e Pareto. Ibid., p.18.

3 NYE JR, Joseph S.. (2004) Soft Power: the Means to Success in World Politics. New York: Public Affairs, p.31. 
no sistema internacional, em geral, e no complexo de segurança regional (CSR) em que estiverem inseridos, em particular. Em outras palavras, quanto mais "insumos de poder"4 um determinado país periférico detiver e quanto mais encarar as relaçóes interestatais a partir de um ponto de vista de inimizade-rivalidade, maior será sua tendência a priorizar a força armada. Por outro lado, aos países da periferia desprovidos desses insumos pouco resta além da manutenção de um quantum mínimo de poder militar passível de ser utilizado na garantia de sua segurança doméstica.

\section{O Sistema Internacional Contemporâneo}

Para que seja possível compreender o papel do poder militar nas Relações Internacionais (RI) contemporâneas, é imprescindível deixar claro qual moldura teórica fornecerá os parâmetros a partir dos quais a realidade mundial será interpretada. O construtivismo wendtiano parece um bom ponto de partida com vistas à superação do impasse representado pelas profecias auto-realizáveis do neo-realismo. No entanto, conforme argumenta Barry Buzan, a teoria de Wendt ganha capacidade preditiva se incorporar alguns elementos do realismo. ${ }^{5}$ Para o primeiro, o sistema internacional seria passível de melhor compreensão se os cálculos de polaridade fossem acrescidos de considerações sobre a identidade dos principais atores estatais. ${ }^{6}$

De modo a justificar seu esquema conceitual, Buzan procurará definir os termos em que a inter-relação polaridade/identidade se processa no mundo atual. Nesse sentido, uma de suas contribuições mais importantes é a de tentar delimitar o que chama de "teoria da polaridade complexa". Para tanto, desenvolve uma tipologia em que são diferenciados três tipos de Estados: superpotências, grandes potências e potências regionais. ${ }^{7}$ As superpotências teriam as seguintes características: possuem interesses globais multifacetados e são capazes de os defender das mais variadas maneiras, em qualquer parte do mundo, sobretudo por meios ideológicos, político-militares e/ou econômicos; da mesma forma, são percebidas pelos demais atores relevantes da cena internacional como possuidoras do estatuto de superpotência e atribuem a si próprias esse estatuto - tendo peso decisivo na conformação da ordem mundial em seus diversos aspectos. As grandes

\footnotetext{
4 Não se pretende oferecer uma definição precisa de insumos de poder, uma vez que o autor acredita que eles não possam ser convenientemente mensurados tendo em vista sua característica relacional. Alguns deles seriam os seguintes: população, território, recursos naturais, pujança econômica, desenvolvimento científicotecnológico, capacidade de persuasão, pujança cultural etc.

5 BUZAN, Barry. (2004) The United States and the Great Powers: World Politics in the Twenty-First Century. Cambridge: Polity Press, p.1-11.

6 Ibid., p.28.

7 Os Estados que não se incluem em nenhuma das 3 categorias não são considerados por exercerem papel marginal no que diz respeito à estruturação do sistema internacional. Pode-se chamá-los simplesmente de potências.
} 
potências, por sua vez, teriam o seguinte perfil: seu espectro de atuação externa não tem alcance verdadeiramente global, ou o tem somente em setores específicos; a grande potência é aquela que é percebida pelos demais Estados como possível futura candidata ao estatuto de superpotência ou, em outro sentido, como superpotência declinante. Finalmente, as potências regionais são Estados cujas capacidades representam dados fundamentais para o equilíbrio de uma região, mas que não exercem papel sistêmico relevante; a importância regional desse tipo de potência permite que sejam capazes de atuar como mediadoras entre o plano intenacional e a sua zona imediata de influência.

Com os elementos acima mencionados em mente, o autor afirma haver uma distribuição de pólos clara no pós-Guerra Fria: uma superpotência (EUA) acrescida de quatro grandes potências (UE, Japão, China e Rússia). ${ }^{8}$ O esquema $1+4$ teria a vantagem de melhor especificar a distribuição de poder e a distinção qualitativa entre super e grandes potências. De acordo com Buzan, ainda que a redução da análise a apenas cinco atores, que representam o núcleo duro da estrutura do sistema internacional, seja útil, ela continuaria permitindo um número muito grande de resultantes. Para diminuir a complexidade que derivaria de suas várias configuraçōes possíveis e gerar prediçôes mais robustas, o esquema $1+4$ deveria ser acompanhado da determinação das identidades dos atores e de sua inter-relação. A melhor forma de fazê-lo seria por meio da construção de cenários. De maneira geral, Buzan utiliza os princípios das três culturas da anarquia propostas por Wendt (inimizade, rivalidade e amizade) para caracterizar o sistema internacional. O faz, contudo, sem optar por um princípio unívoco, considerando viável que dois princípios convivam simultaneamente, desde que não representem extremos do contínuo. Inimizade e rivalidade poderiam coexistir, da mesma forma que rivalidade e amizade. O sistema internacional contemporâneo seria, em sua opinião, marcado pela predominância de uma cultura da anarquia calcada em relações de rivalidade/amizade. A despeito dessa demarcação genérica, seria igualmente necessário determinar os traços mais importantes da identidade dos atores gerados no plano doméstico - forma de especificar de que modo aquela exerceria influência sobre a cultura da anarquia dominante - bem como sua estabilidade. ${ }^{9}$

Assim, passa a ser crucial para o entendimento do futuro do sistema internacional determinar se a identidade americana se transformará de modo a reverter a percepção de ego e alter prevalecente até o 11/9. Note-se que, apesar das

\footnotetext{
8 A inclusão de China e Rússia no rol de grandes potências, por parte de Barry Buzan, ilustra as dificuldades de classificação objetiva dos Estados em categorias genéricas como a de "Estados periféricos". Isso pois a primeira parece encontrar-se em um estádio incipiente de transição da periferia para o centro do sistema capitalista mundial - além de contar com enormes recursos humanos e materiais. A Rússia, por sua vez, encontra-se em declínio relativo, tendo perdido a condição de superpotência. Mesmo no auge de seu poder, ela jamais fez parte do núcleo central do capitalismo. Permanece classificada como grande potência em função de sua significativa capacidade militar (nuclear, essencialmente) e de seus vastos recursos humanos e materiais.
}

9 Buzan menciona os graus de internalização da cultura propostos por Wendt, mas não os utiliza sistematicamente. 
identidades tenderem a se estabilizar em padrões relativamente estáveis, elas podem mudar mais rapidamente do que o poder. A ocorrência de eventos imponderáveis de grande impacto, como os atentados terroristas contra Nova Iorque e Washington, são capazes de contribuir para o início ou o aprofundamento de mudanças no perfil identitário de uma nação. Embora essas transformações jamais sejam imediatas, é possível conceber que se processem em anos, enquanto modificações não-violentas (e.g. por meio de variações de poder econômico) do ranking das principais potências levam décadas para se materializarem. Nesse sentido, a guinada agressiva na política externa norte-americana pós-11/9 não pode ser explicada como simples derivação de um incremento do poder dos EUA, o que claramente não poderia ocorrer de forma instantânea, ou como uma reação "necessária" à agressão sofrida. ${ }^{10} \mathrm{~A}$ assunção de um perfil imperial por parte dos policy-makers daquele país valeu-se do mesmo "estoque" de poder disponível anteriormente, resultando do fortalecimento de corrente de opinião que concebe a identidade nacional norte-americana como insegura, moralmente superior e belicosa.

Buzan supõe que, em função da profunda implantação dos valores liberais, dificilmente a sociedade dos EUA aceitaria assumir os custos políticos, econômicos e morais do imperialismo. No entanto, o espectro de possibilidades relacionadas à identidade da única superpotência permanece vasto. Se as suposições de Buzan estiverem corretas, a configuração do sistema internacional contemporâneo não deve sofrer modificações substanciais a médio prazo. A perdurar o esquema $1+4 \mathrm{em}$ seus lineamentos essenciais, pode-se sustentar que o futuro nível de conflitividade do sistema internacional deverá permanecer moderado no que se refere às guerras entre Estados. ${ }^{11}$ Não há razão para acreditar, contudo, que as disparidades entre países e entre classes dentro de países venham a diminuir. A manutenção dessa circunstância, acrescida do aprofundamento das contradições intrínsecas aos Estados periféricos em um contexto de crise dos tradicionais paradigmas de governança, indica a permanência de fortes tensôes sociais no mundo em desenvolvimento. Logo, a eclosão de guerras civis e movimentos insurrecionais deverá continuar a ser um elemento constante da paisagem internacional - o que permite supor que as operações de manutenção da paz se manterão importantes. Deve-se considerar, também, a instabilidade que o chamado terrorismo "catastrófico"12 pode gerar tanto

10 Esse comentário tem por fim afirmar que a reação dos EUA aos atentados de 11/9 poderia ter-se dado de variadas formas. Inclusive com a busca de soluçôes cooperativas para o enfrentamento do fenômeno do terrorismo.

11 De acordo com o projeto "Correlates of War", atualizado até 1997, apenas uma guerra interestatal (Golfo) ocorreu depois do fim da Guerra Fria, enquanto 24 "intra-wars" tiveram lugar entre 1990 e 1997. Ver SARKEES, Meredith Reid. (2000) "The Correlates of War Data on War: An Update to 1997," Conflict Management and Peace Science, 18/1, p.123-144.

12 Que nada mais é do que o terrorismo que se vale dos meios tecnológicos proporcionados pelo atual estádio de desenvolvimento científico. Pode-se agregar ao conceito, contudo, o eventual caráter suicida das açôes terroristas e a eventual ausência dos requisitos políticos que caracterizaram esse tipo de atividade no passado recente. 
na periferia quanto no centro do sistema e o fato de que a proliferação de armas de destruição em massa deverá manter-se como um possível foco de conflito.

A despeito do quadro anteriormente delineado, é preciso mencionar algumas tendências que podem vir a modificar o seu sentido geral. Sinteticamente, essas tendências poderiam ser assim enumeradas: a) aprofundamento do fosso tecnológico entre os exércitos de países desenvolvidos e em desenvolvimento, com ênfase nas transformações suscitadas pelo aumento do alcance, letalidade, precisão e automação dos sensores e plataformas de combate - além da perspectiva iminente de militarização do espaço; b) intensificação dos efeitos da degradação ambiental sobre os ecossistemas, além da aparente aceleração da mudança climática e da redução das fontes de suprimento de água potável; c) progressivo esgotamento das reservas conhecidas de matérias-primas essenciais como o petróleo; d) ampliação do número de cidadãos de países pobres em relação ao número de cidadãos de países ricos, causada pelas baixas taxas de natalidade encontradas nos primeiros; e) ampliação do diferencial de renda entre países ricos e pobres.

Em síntese, a configuração das relações interestatais deve manter um perfil próximo ao atual até 2020. Contudo, as ameaças não-estatais, como o terrorismo, e os problemas resultantes da escassez de matérias-primas, do desequilíbrio ambiental e da disparidade de poder podem vir a gerar choques violentos - particularmente entre centro e periferia. A força armada, nesse contexto, continuará a ser importante. A fungibilidade do poder militar deverá ser moderada, mas de forma alguma igual a zero. A competição entre Estados não será eliminada e, por conseguinte, os usos indiretos da força armada permanecerão operacionais.

\section{O complexo de segurança da América do Sul}

De acordo com Buzan, Waever e de Wilde, um complexo de segurança regional poderia ser definido da seguinte forma: “(...) um grupo de unidades cujos principais processos de securitização, dessecuritização, ou ambos, estão tão interligados que os seus problemas de segurança não podem ser corretamente analisados ou resolvidos independentemente um do outro."13 Assim, ao abordar a problemática de segurança da América do Sul, pretende-se contextualizar o ambiente estratégico primordial em que o Brasil está inserido. Nesse sentido, parecem não restar muitas dúvidas de que o subcontinente encontra-se entre as regiōes menos violentas do planeta quando se considera a ocorrência de conflitos interestatais. Ao longo do século XX, especialmente a partir de 1950, as guerras têm sido esporádicas, curtas e pouco mortíferas. ${ }^{14}$

13 BUZAN, Barry, WAEVER, Ole, De WILDE, Jaap. (1998) Security: a new framework for analysis. Boulder: Lynne Rienner Publishers, p.201.

14 A definição de guerra utilizada na literatura é a seguinte: conflito armado em que há mais de 1000 mortos no campo de batalha. Ver MARES, David R.. (2001) Violent Peace: Militarized Interstate Bargaining in Latin America. New York: Columbia University Press, p.32. 
O quadro sucintamente esboçado acima poderia sugerir que está em marcha a consolidação de uma comunidade pluralista de segurança na região ou até mesmo que a cultura da anarquia prevalecente nesta última ter-se-ia estabilizado em torno de uma lógica kantiana. Conforme será possível perceber adiante, esse não parece ser o caso. Além da dificuldade intrínseca em mensurar o grau de internalização da cultura da anarquia dominante, o simples fato de haver reduzido número de guerras não exclui a dimensão corretiva do poder das relações entre os Estados sul-americanos. David R. Mares, por exemplo, aponta a insuficiência da análise do relacionamento de segurança entre os países da região unicamente baseada na dicotomia guerra/ paz. ${ }^{15}$ Para ele, esta última teria como consequência o mascaramento de uma ampla gama de possibilidades de utilização do poder militar que precedem o conflito bélico propriamente dito. Contrariamente ao senso comum, as estatísticas de que Mares faz uso dão conta de que, entre 1945 e 1997, a América Latina foi palco de três guerras interestatais (duas na América do Sul e uma na América Central). Esse número é maior, por exemplo, do que o registrado na África (duas), Nordeste da Ásia (uma) e América do Norte (nenhuma). ${ }^{16}$ No período acima aludido, somente o Oriente Médio, em que ocorreram nove guerras, pode ser considerado significativamente mais tendente à guerra que a América Latina.

É com base nessa constatação que Mares procura comprovar sua tese de que predominaria na América Latina uma "paz violenta". Entre 1884 e 1993, teriam havido 237 episódios de disputas interestatais militarizadas (DIMs) na região - 110 na América Central e 127 na América do Sul. No período que vai de 1980 a 1997, correspondente ao retorno da democracia à maioria dos Estados latino-americanos, teriam ocorrido 52 DIMs - sendo que 16 delas, ocorridas depois de 1990, se deram entre díades democracia/democracia. ${ }^{17}$ Se esses dados estiverem corretos, poder-se-ia afirmar que o subcontinente sul-americano não é tão pacífico quanto a resultante de uma análise baseada na dicotomina guerra/paz quer fazer crer. $\mathrm{Na}$ verdade, os dados compilados por Mares indicam que a América Latina, em geral, e a América do Sul, em particular, possuem nível de conflitividade interestatal intermediário. $\mathrm{O}$ trabalho por ele realizado confirma, não obstante, a baixa tendência à escalada dos conflitos até seu limite lógico. Em qualquer circunstância, os elementos mais importantes do ponto de vista do estudo que aqui se realiza, derivados de "Violent Peace", são aqueles relacionados ao questionamento de uma visão idílica sobre a segurança na América do Sul. A despeito dessas considerações, que matizam a idéia de uma regiāo fundamentalmente pacífica, deve-se admitir que as questões de segurança do subcontinente não são cruciais para o equilíbrio do sistema internacional.

15 Ibid., p.28-51.

16 Ibid., p.37.

17 Idem. 


\section{O papel do Brasil no entorno sul-americano do ponto de vista da segurança}

O Brasil desempenha papel primordial na conformação do CSR da América do Sul. Na condição de potência regional periférica, interessa-se pela manutenção da estabilidade no subcontinente como forma de evitar o desvio de recursos diplomáticos escassos para o tratamento de temas não diretamente relacionados à problemática do desenvolvimento. Nesse sentido, a política externa brasileira apresenta-se fundamentalmente como defensora do status quo no que se refere às questōes de segurança da região. A satisfação territorial e a não securitização de ameaças emanadas dos países lindeiros permitem que o País priorize a dimensão do desenvolvimento em detrimento da dimensão estratégico-militar, tendo em vista a persistência de grandes disparidades sociais no plano doméstico. ${ }^{18}$ Logo, as políticas externa e de defesa têm-se caracterizado, ao menos no passado recente, por grande cautela quanto à afirmação de aspiraçôes à liderança ou hegemonia. ${ }^{19}$

Pode-se argumentar que haveria uma rationale implícita na postura brasileira de fomento da estabilidade regional e de negação de pretensões hegemônicas. Essa basear-se-ia na percepção de que as desigualdades sociais representam um handicap à participação nacional em questóes que envolvam o uso ou a possibilidade de uso do poder militar. ${ }^{20}$ De outra perspectiva, a adoção de atitudes mais assertivas, no campo da segurança, poderia ser contraproducente para o avanço dos interesses econômico-comerciais brasileiros, ao dar ensejo a ressentimentos e desconfianças nos Estados vizinhos. Logo, a diplomacia nacional, desde ao menos a gestão do Barão do Rio Branco, buscou evitar a eclosão de conflitos na América do Sul, valendo-se do tradicional repertório do jurisdicismo latino-americano. ${ }^{21}$ Nessa

18 A idéia de "déficit social" como handicap ao incremento do poder militar brasileiro parece ter sido reforçada na Nova República. Pode-se inferir, contudo, que, ao longo da maior parte do século XX, essa concepção não possuiu o estatuto que alcançaria no período pós-autoritário recente. Nesse sentido, as disparidades sociais prevalecentes durante a República Velha não impediram o programa de reaparelhamento naval iniciado em 1904. Não impediram algumas iniciativas de reaparelhamento militar durante o período Vargas. Também não impediram a modernização da Marinha e da Aeronáutica durante o regime militar iniciado em 1964. Sobre o reaparelhamento naval, ver BUENO, Clodoaldo. (2003) Política Externa da Primeira República: os Anos de Apogeu (de 1902 a 1918). São Paulo: Paz e Terra, p.182-197.

19 Para uma discussão mais aprofundada sobre a idéia de liderança brasileira, ver DANESE, Sérgio. ¿ Liderazgo brasileño? (2001) Foreign Affairs en Español. Vol. 1, número 3, Otoño-Inverno, p.157-180. Para um painel sobre a incidência das questōes de segurança (e defesa) sobre a política externa brasileira desde o século XIX, ver Amado Cervo. A dimensão da segurança na política exterior do Brasil. op. cit.

20 “(...) reconhecendo as deficiências e as insuficiências brasileiras decorrentes de problemas internos, bem como a situação de dependência do País no sistema econômico internacional, a diplomacia procurou promover e garantir os interesses nacionais sem criar complicadores que pudessem implicar confrontos desnecessários. Assim, conduziu o jogo político-estratégico na América do Sul indiferente à presença da força militar.” CAVAGNARI, Geraldo Lesbat. Estratégia e Defesa (1960-1990). In: ALBUQUERQUE, José Augusto Guilhon (org.). (2000) Sessenta anos de política externa brasileira (1930-1990): Prioridades, atores e políticas. São Paulo: Annablume/NUPRI/USP, p. 119.

21 Ver CERVO, Amado. Relações Internacionais do Brasil. In: CERVO, Amado (org.). (1994) O desafio internacional: a política exterior do Brasil de 1930 a nossos dias. Brasília: Editora Universidade de Brasília, p. $9-58$. 
linha, o processo de integração das economias do subcontinente, impulsionado nos anos 90 pelo Mercosul, parece ter constituído elemento de reforço da lógica não-confrontacionista brasileira. ${ }^{22}$

A menção anterior à existência de uma rationale "implícita" ao nãoconfrontacionismo foi proposital. Ela deriva da noção de que essa possui um forte aspecto tático ou contingente. Se, por um lado, é lícito defender a tese de que a busca da conciliação de interesses antagônicos encontra respaldo na identidade nacional, por outro, é perfeitamente plausível sugerir que ela ocorre em razão das debilidades do poder brasileiro ao longo do século XX. O patrono da diplomacia não poderia ser mais explícito: "Os meios persuasivos são, a meu ver, os únicos de que se lança mão, para sair-se bem de negociação complicada como esta (litígio com a França sobre o Amapá), uma nação como o Brasil, que ainda não dispõe de força suficiente para impor sua vontade a uma grande potência militar." ${ }^{23}$ Em outras palavras, não só a estrutura de idéias seria responsável pela política externa conciliatória do País, mas também a estrutura material. Ademais, se parece certo que a tradição jurisdicista da política externa nacional corrobora o não-confrontacionismo, o realismo também o faz por motivos distintos. ${ }^{24}$ Pela lógica desse último, esposada por Rio Branco, é justamente a ausência de recursos de poder, em escala adequada, que indica o acerto da busca da resolução pacífica dos conflitos.

Logo, a preponderância da diplomacia sobre as Forças Armadas, no Brasil, resulta da conjunção de uma identidade nacional conciliatória com a persistência de um arranjo de polaridade específico em que falta à potência regional capacidade efetiva de projeção multidimensional de poder. Ainda sobre a moderação da política externa brasileira, caberia tecer algumas considerações que coloquem em perspectiva a sua influência sobre a baixa prioridade atribuída ao fortalecimento da capacidade de defesa nacional. Em primeiro lugar, deve-se discutir o que "moderação" significa. Pode-se dizer que o termo teria dois significados normativamente distintos. Concebido como prudência, temperança, precisão, claridade de julgamento, esse construto poderia ser considerado essencialmente positivo para a condução de qualquer política externa. Encarado como sinônimo de indecisão, tibieza, ausência de resolução, o termo adquiriria conotação negativa. Diante disso, a moderação só pode ser tomada como um valor a ser perseguido se for compreendida em seus aspectos virtuosos. Nenhuma das características

22 A idéia de que a intensificação do comércio com os países vizinhos dependeria de estabilidade política regional tem sido uma constante do plano declaratório da política externa brasileira no passado recente. Subjacente a ela encontram-se dois conceitos: maior fluxo de comércio com os países vizinhos significa maiores oportunidades de desenvolvimento econômico e maior fluxo de comércio com os países vizinhos significa vínculos políticos mais estreitos. Não há espaço neste trabalho para uma discussão aprofundada sobre as implicaçôes do aprofundamento dos laços comerciais do Brasil com os países da América do Sul.

23 Barão do Rio Branco apud Clodoaldo Bueno, op.cit., p.220.

24 Realismo entendido como matriz de teoria política cujo foco recai sobre as relações de poder entre os Estados, não como pragmatismo - aliás, outra característica secular da política externa brasileira. 
positivas do construto implica o abandono da política de defesa como um tema de fundamental importância. Em resumo, deve-se ter presente que não há uma relação necessária entre uma política externa baseada em valores de conciliação/ moderação e a fragilidade militar do País.

O parágrafo anterior serve de caveat em relação a um argumento encontrado nas discussões menos informadas sobre a relação entre política externa e política de defesa no Brasil: o de que haveria uma perfeita harmonia entre a tradição conciliatória mencionada alhures e a fragilidade militar do País. Dito de outra maneira, essa rationale equivocada supõe a existência de simetria exata entre as duas políticas públicas. A inconsistência desse argumento é flagrante, uma vez que pressupõe a existência de uma capacidade de planejamento de políticas públicas improvável, bem como de um nível sem precedentes de subordinação da política de defesa à política externa. Ademais, esse raciocínio desconsidera o fato de que o País, desde a independência em 1822, nunca contou com um aparato de defesa verdadeiramente relevante. ${ }^{25} \mathrm{Em}$ última análise, a rationale em questão vê ordem onde impera a ausência de ordem, o que apenas serve para mascarar os problemas que dizem respeito ao insuficiente grau de articulação entre as políticas em tela.

\section{Entraves domésticos à condução da política de defesa}

Esta seção tem por objetivo utilizar os elementos contextuais anteriores como moldura a partir da qual seja possível agregar a influência decisiva dos fatores domésticos sobre a política de defesa brasileira. Parte-se aqui do axioma básico de que o plano doméstico é mais relevante do que o internacional para a produção da política de defesa. Isso ocorre em função do fato de que os inputs emanados do CSR sul-americano e do nível sistêmico não são suficientemente intensos para suplantar a preponderância da dinâmica burocrática relacionada à gestão dos assuntos militares no Brasil. Assim, a ausência de securitização de ameaças advindas do exterior faria com que a problemática castrense estivesse essencialmente condicionada pela lógica da política doméstica. Nesse sentido, o próprio subdesenvolvimento institucional do País contribuiria para que houvesse dificuldades intrínsecas na tradução de incentivos externos em políticas públicas capazes de lhes dar respostas eficazes. Partindo desse pressuposto, encontram-se no plano interno as razões primordiais para a configuração da política de defesa tal qual praticada desde o fim da Guerra Fria.

Tendo em conta a breve contextualização precedente, pode-se sugerir que alguns fatores são instrumentais para a baixa prioridade atribuída aos temas

25 A Marinha do Brasil usufruiu, durante muitas décadas do século XIX, de supremacia naval na América do Sul. No entanto, isso não significava que a Esquadra nacional fosse relevante em termos mundiais. O Exército, em contraste, jamais foi relevante seja em termos regionais seja em termos mundiais. A Guerra do Paraguai representou episódio de fortalecimento temporário da força terrestre, logo seguido de acentuada desmobilização e sucateamento. 
de defesa no Brasil pós-autoritário: a limitada capacidade de proposição e de fiscalização de políticas públicas complexas por parte do poder Legislativo, a ênfase conferida à problemática do desenvolvimento, a falta de interesse por assuntos militares em função do insulamento burocrático e do histórico de intervenção das Forças Armadas na política, a ausência de securitização de ameaças externas e a maior intensidade da percepção de ameaças internas. Sobre este último fator, deve-se admitir que a dimensão adquirida pela questão da segurança pública ${ }^{26}$ pode ser considerada um dos mais importantes componentes da percepção socialmente compartilhada de que as principais ameaças ao Brasil partem do plano interno, ${ }^{27}$ incidindo pesadamente sobre as questôes de defesa nacional - uma vez que estas não são vistas como prioritárias.

Os elementos previamente explorados, aliados à suposição de que o CSR sulamericano não seria conturbado o suficiente para levar à securitização de ameaças externas, fazem com que a política de defesa nacional seja fortemente condicionada pela dinâmica inercial das ações das três forças. Essa dinâmica foi mantida em seus traços essenciais desde 1989 até os dias de hoje - apesar da implantação do Ministério da Defesa (MD), que permanece incapaz de exercer direção efetiva sobre as Forças Armadas. ${ }^{28}$ Esse fato torna extremamente difícil considerar que as modificações institucionais ocorridas no setor, desde o fim da Guerra Fria, tenham resultado em uma política de defesa renovada. Assim, cada força singular persegue seus próprios objetivos sem preocupação com a compatibilidade, coerência e racionalidade de suas ações em relação às políticas setoriais das demais forças. Sem diretrizes unificadoras claras emanadas do Executivo ou do Legislativo, a política de defesa permanece implícita, não-coordenada e incoerente ao longo do período estudado.

\section{Entraves à articulação entre as políticas externa e de defesa}

$\mathrm{Na}$ seção anterior, procurou-se demonstrar a existência de uma série de entraves que dificultam a condução virtuosa da política de defesa. Nesta seção, por sua vez, pretende-se identificar os fatores que contribuiriam para que a articulação daquela com a política externa também esteja muito aquém do desejável. Antes, contudo, faz-se imprescindível explorar o que se entende por articulação e como seria possível estabelecer um parâmetro para determinar se as políticas externa

26 Sobre a violência urbana no Brasil, ver PERALVA, Angelina. (2000) Violência e democracia: o paradoxo brasileiro. São Paulo: Paz e Terra.

27 Não cabe discutir aqui se essa percepção seria boa ou ruim. Conforme a estrutura de análise conceitual adotada neste livro, supõe-se, com base nas freqüentes manifestações de formadores de opinião locais, que estaria em curso no Brasil um processo de securitização de ameaças internas como o narcotráfico e o crime organizado. Em relação a ameaças externas, não se observa processo análogo.

28 Sobre a implantação do MD, ver OLIVEIRA, Eliézer Rizzo de. (2005) Democracia e Defesa Nacional. Barueri: Manole. 
e de defesa estariam ou não convenientemente articuladas. No presente estudo, compreende-se o conceito aludido como a coordenação entre as duas políticas públicas antes mencionadas visando a maximização dos ganhos (ou minimização dos prejuízos) da ação internacional do Brasil. Nesse sentido, deve-se admitir que a mensuração precisa dos ganhos do País, decorrentes da maior ou menor articulação entre as políticas externa e de defesa, é problemática. Ela, contudo, pode ser estimada por meio de estudos de caso.

Feitas essas considerações preliminares, torna-se forçoso admitir que, no Brasil, se registra um grau de articulação insuficiente entre as políticas de defesa e externa. Essa suposição aplica-se ao período abrangido por este trabalho, mas poderia provavelmente ser estendida como representação da realidade pré-1989. ${ }^{29}$ Uma complexa gama de fatores contribui para que tal ocorra. Contudo, com o objetivo de manter o sentido de síntese deste estudo, serão aludidos apenas quatro fatores que ajudam a explicar o por que da insuficiência acima mencionada: a baixa prioridade da política de defesa, a ausência de direção política efetiva sobre a política de defesa, o perfil não-confrontacionista da política externa e a ausência de mecanismos operacionais de articulação entre as duas. Os fatores apontados inter-relacionam-se, sendo difícil definir o peso relativo de cada um para a existência do fenômeno em análise. Por constituir foco não essencial da presente seção, essa definição não será levada à frente.

Os quatro fatores sumariamente apontados acima somam-se de forma a criar uma série de entraves à articulação entre duas políticas de Estado essenciais - ou que, ao menos, deveriam sê-lo - para a inserção internacional do Brasil. Levando em conta o período pós-Guerra Fria, é lícito afirmar que a política externa sofreu modificações importantes a partir da gestão Collor. O mesmo, contudo, não ocorreu em relação à política de defesa. Logo, as linhas de continuidade permaneceram muito mais fortes no âmbito militar do que no diplomático, o que faz supor que se produziu durante o período uma disjunção cada vez maior entre as políticas em tela. Esta só não se transformou em problema de relevo em face do baixo perfil estratégico do País e do entorno relativamente benigno existente na América do Sul, tendo perdurado a ausência de direção política clara, a ausência de projeto de forças integrado, a ausência de mecanismo efetivo de coordenação diplomático-militar etc. Assim, pode-se inferir que, desde 1989, o discreto perfil estratégico brasileiro foi instrumental para abafar as inconsistências de articulação existentes entre as políticas externa e de defesa.

29 A limitada articulação entre as políticas externa e de defesa, no período pré-1989, pode ser inferida a partir da inexistência de uma entidade que exercesse efetivamente a coordenação entre os próprios ramos das Forças Armadas. Se o nível de articulação entre as próprias políticas setoriais era mínimo, pode-se supor que a articulação entre a política de defesa resultante e a política externa fosse inadequado. Essa é, contudo, uma discussão complexa e que carece de estudos que possam determinar até que ponto as suposições acima mencionadas seriam verdadeiras. 


\section{O Brasil e o mundo em 2020: cenários}

Tendo em vista o exposto e o fato de que se busca conhecer as grandes linhas tendenciais que permitam a extrapolação das feições prováveis das políticas externa e de defesa na próxima década e meia, a utilização dos cenários consubstanciados no exercício 'Brasil 2020', de 1997, não representa obstáculo intransponível. ${ }^{30}$ Esses cenários, contudo, serão compatibilizados com a situação prevalecente nos campos das políticas externa e de defesa, em 2009, que segue abaixo:

\section{Política Externa em 2009}

Mantém inalterada a busca de insumos para o desenvolvimento; Grande ênfase conferida ao processo de integração regional; Ênfase atribuída à rodada de negociaçõos comerciais no âmbito da OMC; Busca de ampliação de relaçôes comerciais com mercados não-tradicionais; Prioridade para a conquista de um assento permanente no Conselho de Segurança das Nações Unidas (CSNU); Prioridade atribuída às parcerias com grandes Estados da periferia; Ampliação da participação brasileira em peacekeeping operations (MINUSTAH); Cobrança dos compromissos das grandes potências em relação aos regimes internacionais de não-proliferação (e.g. TNP), mas sem ruptura com esses regimes;

\section{Política de Defesa em 2009}

Manutenção do baixo perfil militar do País; Incapacidade do MD de exercer coordenação efetiva sobre as forças singulares e seus orçamentos (o que se espera venha a mudar, caso a Estratégia Nacional de Defesa - END - seja efetivamente implementada); Políticas setoriais naval, terrestre e aérea com baixo grau de articulação sistêmica; Virtual falência financeira das forças singulares; ${ }^{31}$ Avançado grau de obsolescência material; Baixa disponibilidade das plataformas de combate; Nível geral de adestramento abaixo do mínimo necessário;

A partir do conhecimento hodierno e da síntese apresentada acima, pode-se, então, extrapolar a plausibilidade de cada um dos cenários do Brasil 2020. Nesse sentido, o Cenário Abatiapé (positivo) possui baixíssima plausibilidade, o Baboré (intermediário) média/baixa e o Caaetê (negativo) média/alta.

\section{Política externa e política de defesa brasileiras, visões alternativas}

Nesta seção, pretende-se realizar duas tarefas inter-relacionadas. A primeira é de cunho essencialmente normativo e prende-se à necessidade de definir o que

30 Ver Cenários Exploratórios Brasil 2020. (1997) Brasília: SAE/SAA/PR.

31 Gastos de custeio crescentes (em especial salários, aposentadorias e pensões) representam cerca de $80 \%$ do orçamento, sem levar em consideração eventuais contingenciamentos que incidem essencialmente sobre a parcela de $20 \%$ restante. 
seria a melhor articulação possível entre as políticas externa e de defesa brasileiras. Essa definição permitirá que se coteje suas características com aquelas decorrentes da articulação entre ambas as políticas em cada um dos cenários exploratórios. A caracterização dessas últimas, em função do contexto específico dos cenários, constitui a segunda tarefa a ser realizada.

No caso de uma potência regional periférica como o Brasil, em que prevalecem sérias disparidades sociais, o aumento das margens de autonomia e de soberania não poderá estar centrado apenas no incremento do poder militar. Este, porém, é imprescindível para que o desenvolvimento nacional possa seguir seu curso sem interferências externas cerceadoras. Da mesma forma, ele é crucial para ampliar as possibilidades de atuação internacional brasileira. A inexistência de incompatibilidades fundamentais entre os valores esposados pela população local e a da superpotência - único Estado com reais capacidades de coagir o Brasil militarmente - faz com que não haja demanda imediata no sentido da construção de um aparato dissuasório capaz de impedir uma eventual tentativa de coerção norte-americana. ${ }^{32} \mathrm{~A}$ despeito do que precede, a posse de uma limitada mas crível força de dissuasão convencional já seria suficiente para dar conta das principais necessidades de defesa do País na próxima década e meia. Uma capacidade de dissuasão com esses contornos poderia não só tornar mais custosa qualquer ação militar contra interesses brasileiros, mas também contribuir com o esforço de desenvolvimento econômico propriamente dito.

Tendo em consideração a importância desses dois valores para o desenvolvimento, o autor sustenta que todos os demais devam estar, em princípio, subordinados a eles. ${ }^{33}$ Logo, uma das facetas mais relevantes da articulação entre as políticas externa e de defesa tem a ver com a própria admissão de que a primeira precisa contar com a segunda! Essa suposição não é tão óbvia assim no caso brasileiro, em que prevalece um enorme desconhecimento sobre temas militares e uma perspectiva ingênua sobre a instrumentalidade da força armada. Estabelecido esse princípio básico, a articulação ideal deveria obedecer a alguns parâmetros: (I) existência de mecanismos formais e informais de diálogo entre as burocracias envolvidas na formulação e na implementação das duas políticas aqui estudadas; (II) os mecanismos existentes devem ser fluidos e consequentes; (III) o diálogo institucional proporcionado por esses mecanismos deve ser plenamente congruente com as diretivas emanadas do Presidente da República - Comandante em Chefe das Forças Armadas e responsável último pela política

32 Para garantir ampla capacidade dissuasória contra os EUA, seria preciso contar com grandes e eficientes forças nucleares e convencionais. No caso de um choque de voliçôes sério com a superpotência, para garantir dissuasão eficaz não basta a um terceiro Estado ter somente forças nucleares ou somente forças convencionais. É preciso ter as duas. Sobre a teoria da dissuasão, ver MORGAN, Patrick M.. (2003) Deterrence Now. Cambridge: Cambridge University Press.

33 Como frequentemente ocorre em RI, as circunstâncias não permitem generalizações heróicas. Em determinados contextos, outros valores, como o respeito ao direito internacional, podem ter precedência sobre a autonomia e a soberania. 
externa - e com a Constituição Federal; (IV) a implementação das duas políticas deve ter por base não somente objetivos de curto, mas também de médio e longo prazos - derivados de amplo consenso político sobre a "grande estratégia" nacional $^{34} ;(V)$ a implementação das políticas deve ser a mais congruente possível, de modo que uma não venha a minar a outra;

Logo, a articulação mais provável entre as políticas externa e de defesa seria a seguinte em cada um dos cenários anteriormente alinhavados:

\section{Cenário Abatiapé - articulação entre PEXT e PDEF}

Existência de mecanismos formais e informais de diálogo entre as burocracias envolvidas na formulação e na implementação das duas políticas; Mecanismos existentes são relativamente fluidos e consequentes; Diálogo institucional é bastante congruente com as diretivas emanadas do Presidente da República e da Constituição Federal; Chega-se a consenso abrangente sobre uma grande estratégia nacional que parametriza a implementação das PEXT e PDEF no médio e longo prazo; Implementação das políticas é relativamente congruente entre si; Constróise capacidade dissuasória com credibilidade suficiente para impedir tentativas de coação militar; PEXT utiliza com frequência os instrumentos proporcionados pela PDEF; PDEF amplia a capacidade de barganha da PEXT;

\section{Cenário Baboré - articulação entre PEXT e PDEF}

Existência de mecanismos formais e informais de diálogo entre as burocracias envolvidas na formulação e na implementação das duas políticas; Mecanismos existentes são relativamente fluidos e consequentes; Diálogo institucional é relativamente congruente com as diretivas emanadas do Presidente da República e da Constituição Federal; Não se chega a consenso abrangente sobre uma grande estratégia nacional que parametrize a implementação das PEXT e PDEF no médio e longo prazo, mas algumas diretrizes são objeto de acordo; Implementação das políticas é relativamente congruente entre si; Constrói-se capacidade dissuasória limitada, mas suficiente para dificultar tentativas de coação militar; PEXT utiliza os instrumentos proporcionados pela PDEF; PDEF amplia apenas moderadamente a capacidade de barganha da PEXT;

\section{Cenário Caaetê - articulação entre PEXT e PDEF}

Existência de mecanismos formais e informais de diálogo entre as burocracias envolvidas na formulação e na implementação das duas políticas; Mecanismos

34 O termo grande estratégia é, geralmente, utilizado como sinônimo de projeto nacional de longo prazo. Contudo, muitas vezes há ênfase especial em seus aspectos mais propriamente relacionados à segurança do Estado no sistema internacional. 
existentes são relativamente fluidos, porém pouco consequentes; Diálogo institucional é relativamente congruente com as diretivas emanadas do Presidente da República e da Constituição Federal; Não se chega a consenso sobre uma grande estratégia nacional que parametrize a implementação das PEXT e PDEF no médio e longo prazo; Implementação das políticas não é necessariamente congruente entre si; Não se constrói capacidade dissuasória suficiente para dificultar tentativas de coação militar; PEXT utiliza de maneira limitada e esporádica os parcos instrumentos proporcionados pela PDEF; PDEF não amplia a capacidade de barganha da PEXT, antes limita-a;

\section{Afinal, o poder militar importa no caso do Brasil?}

A resposta inequívoca à pergunta que dá título à conclusão deste estudo é de que o poder militar importa no caso do Brasil, uma vez que a força armada pode auxiliar a política externa em seu esforço de ampliação da capacidade de barganha e da autonomia do País. Devido à sua relevância intrínseca, ele não pode, em hipótese alguma, ser negligenciado como ferramenta útil à consecução dos interesses nacionais. A manutenção de uma estrutura militar precária como a atual reduz o campo de manobra da política externa, limitando sua latitude e expondo o País a condicionalidades derivadas do eventual surgimento de disputas com potências estrangeiras. A ausência de capacidades militares adequadas contribui também para a diminuição do soft power nacional. Assim, ao Ministério das Relações Exteriores do presente caberia, como fez o patrono da diplomacia brasileira há quase um século ${ }^{35}$, engajar-se no debate público e intragovernamental relativo à reestruturação e reaparelhamento das Forças Armadas.

$\mathrm{Na}$ linha do acima exposto, a maior capacitação das forças armadas brasileiras permitiria que se pudesse explorar iniciativas de produção conjunta de armamentos com os paises lindeiros. O Brasil poderia liderar esse processo, que, a par de incentivar a indústria bélica nacional, aproximaria ainda mais os estamentos militares dos Estados sul-americanos (iniciativa potencialmente auspiciosa prevista nas deliberações do recém-criado Conselho Sul-Americano de Defesa). Além de demonstrar as intenções não hegemônicas do País, o incremento de iniciativas dessa natureza faria com que se estreitasse o relacionamento político na região, assim como determinaria redução dos custos de aquisição de sistemas de armas. Isso incentivaria a criação de um pequeno cluster de indústrias bélicas no subcontinente, capitaneada pelo Brasil. Poder-se-ia cogitar, inclusive, o fornecimento de modo sistemático, por parte das Forças Armadas, de material de emprego militar de segunda-mão para os países menos dotados de recursos da América do Sul. Uma maior assistência militar aos Estados do CSR constituiria gesto político importante

35 Não se deve esquecer que o Barão do Rio Branco teve participação destacada nas discussões que deram origem ao programa de reaparelhamento naval empreendido na década de 1910. 
que, no longo prazo, poderia reduzir a influência exercida pela superpotência sobre os exércitos da região. Os efeitos desse tipo de parceria seriam francamente favoráveis à intenção brasileira de aumentar a coesão política e econômica sulamericana, ampliando o poder de barganha do País tanto no relacionamento com seus vizinhos quanto com potências extra-regionais.

O poder de barganha nacional seria adicionalmente intensificado se a nação contasse com a capacidade de participar ativamente de esforços de manutenção da paz em suas diversas modalidades. A participação em missões desse gênero, ademais de contribuir para o aumento do soft power do País, poderia servir como justificativa política para a maior aplicação de recursos no setor de defesa. A despeito do que precede, acredita-se que a contribuição com esse tipo de missão não deve se tornar o alfa e o ômega da política de defesa brasileira. Ainda que a imposição da paz possa ter semelhanças com o emprego convencional das forças armadas em conflitos interestatais, há que se admitir que as funções de peacekeeping estão muito mais próximas das de caráter parapolicial do que das relacionadas ao combate entre exércitos regulares. $\mathrm{O}$ risco decorrente da superestimação da importância das atividades de manutenção da paz seria o de especializar as Forças Armadas brasileiras nesse tipo de missão, negligenciando a centralidade das tarefas clássicas de defesa da soberania. A despeito desse caveat, no plano sul-americano, a política externa poderia valer-se da existência dessa capacidade para induzir, se assim entender conveniente, a formação de uma força de pronto emprego regional para atuação seletiva em missões de paz. Uma iniciativa como essa seria congruente com o fortalecimento da unidade política da América do Sul, servindo também como medida de fomento da confiança.

Outra capacidade militar que seria extremamente útil, em situações de contingência, é aquela representada pela projeção limitada de poder além fronteiras. Tendo em vista os crescentes interesses brasileiros em países vizinhos, bem como a significativa instabilidade política, econômica e social em muitas das nações lindeiras, torna-se relevante que as Forças Armadas do País tenham condições de empreender ações pontuais de garantia desses interesses. Essas ações envolveriam a proteção de nacionais durante crises em que houvesse ameaças à sua integridade física, a proteção de ativos estratégicos, o fornecimento de apoio humanitário em situações de calamidade, entre outros. Essa capacidade, fundamental em casos de extrema gravidade, pode ser utilizada pela política externa brasileira para aumentar o poder de barganha nacional no relacionamento com os demais países sul-americanos. Logo, a capacidade de projetar, no espaço sul-americano, uma pequena mas robusta força militar, parece corresponder a uma importante ferramenta política passível de ser instrumentalizada pelo Itamaraty.

As três iniciativas sucintamente mencionadas acima, derivadas do incremento das capacidades militares do País, representam exemplos claros de como uma mudança qualitativa na política de defesa poderia proporcionar maior latitude de atuação à política externa. Também suscitam a reflexão sobre as formas pelas 
quais a última poderia contribuir para a mudança da primeira. Caberia esclarecer, contudo, que as duas políticas públicas mencionadas, por melhor articuladas que sejam, não são capazes de modificar sozinhas a realidade futura. Qualquer cenário prospectivo depende, para sua concretização, de um sem número de variáveis. Isso quer dizer que a busca de excelência na articulação entre as políticas externa e de defesa constitui um exercício vazio? A resposta é negativa. Logo, ainda que o porvir venha a se materializar em sua versão menos positiva, o País só tem a ganhar se for capaz de articular satisfatoriamente os assuntos diplomáticos e militares.

Recebido em 25 de Março de 2009 Aprovado em 10 de Julho de 2009

\section{Resumo}

Este artigo pretendeu refletir sobre a instrumentalidade do poder militar para a política externa brasileira no pós-Guerra Fria. Definiu-se a moldura teórica de interpretação do relacionamento entre unidades soberanas. Discutiram-se as peculiaridades do complexo de segurança da América do Sul e o papel do Brasil na sua conformação. Analisaram-se os entraves à condução virtuosa da política de defesa e as dificuldades de articulação entre esta e a política externa. Sugeriram-se iniciativas visando ao aprimoramento da interface entre as políticas externa e de defesa.

\section{Abstract}

This article intended to investigate the instrumentality of military power for Brazil's foreign policy in the post-Cold War era. A theoretical framework for the interpretation of sovereign unities' relationship was delimitated. South America's security complex and Brazil's role in its conformation were discussed. Problems related to Brazil's defense policy and the difficulties concerning its proper articulation with foreign policy were analyzed. Finally, initiatives were suggested that could contribute to the improvement of Brazil's foreign and defense policies' interface.

Palavras-chave: Relações Internacionais; Poder Militar; Política Externa do Brasil. Keywords: International Relations; Military Power; Brazil's Foreign Policy. 